Provided for non-commercial research and educational use only. Not for reproduction or distribution or commercial use.

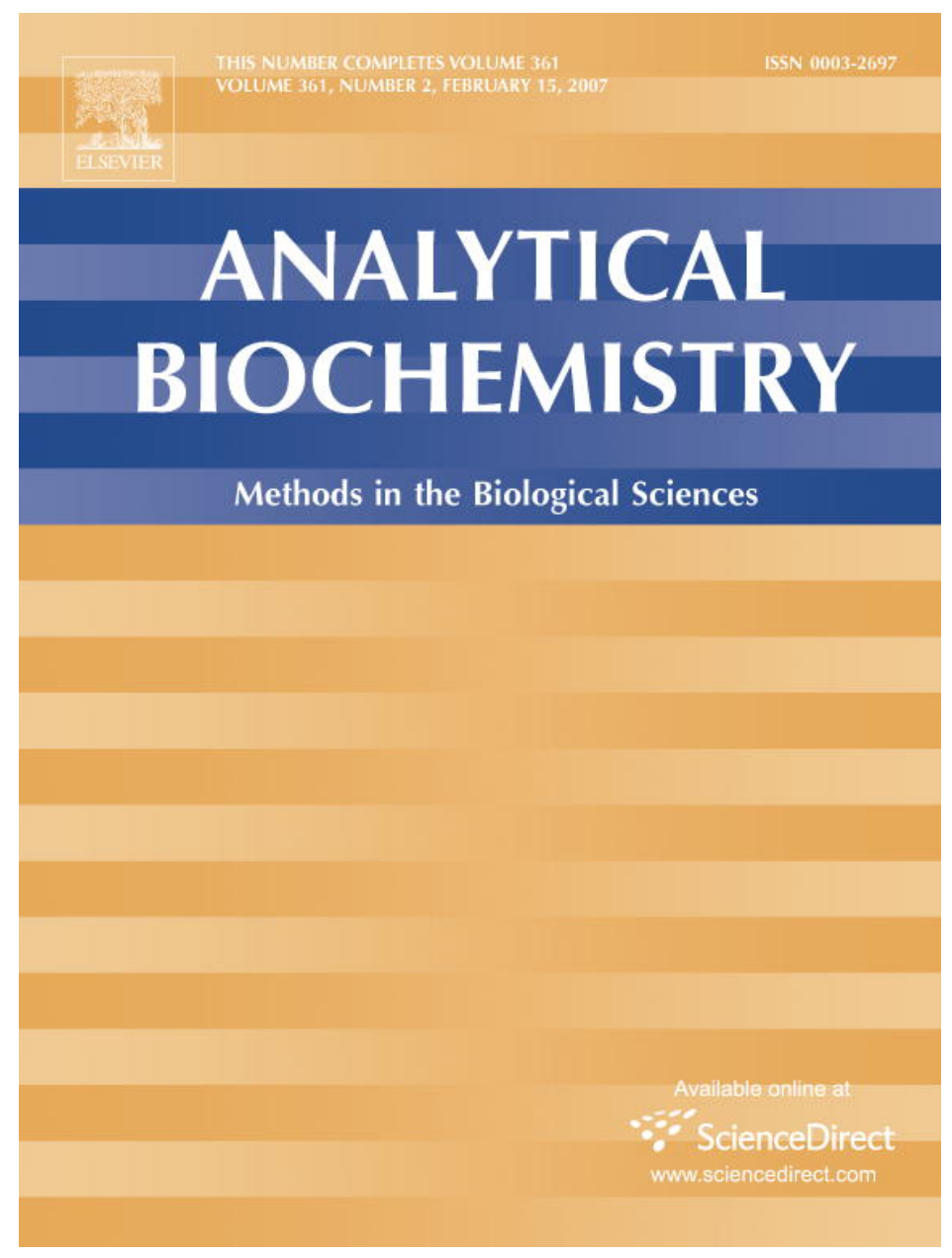

This article was originally published in a journal published by Elsevier, and the attached copy is provided by Elsevier for the author's benefit and for the benefit of the author's institution, for non-commercial research and educational use including without limitation use in instruction at your institution, sending it to specific colleagues that you know, and providing a copy to your institution's administrator.

All other uses, reproduction and distribution, including without limitation commercial reprints, selling or licensing copies or access,

or posting on open internet sites, your personal or institution's website or repository, are prohibited. For exceptions, permission may be sought for such use through Elsevier's permissions site at: 


\title{
Evaluation of the lipophilic properties of opioids, amphetamine-like drugs, and metabolites through electrochemical studies at the interface between two immiscible solutions
}

\author{
Rubin Gulaboski ${ }^{\mathrm{a}, \mathrm{b}, \mathrm{j}, *}$, M. Natalia D.S. Cordeiro ${ }^{\mathrm{a}, *}$, Nuno Milhazes ${ }^{\mathrm{c}}$, Jorge Garrido ${ }^{\mathrm{d}}$, \\ Fernanda Borges ${ }^{e}$, Miguel Jorge ${ }^{a}$, Carlos M. Pereira ${ }^{b}$, Ivan Bogeski ${ }^{f}$, \\ Aluska Helguera Morales ${ }^{\text {g,h }}$, Blaze Naumoski ${ }^{i}$, A. Fernando Silva ${ }^{\text {b' }}$ \\ ${ }^{\text {a }}$ REQUIMTE, Faculdade de Ciências, Universidade do Porto, Rua do Campo Alegre, 687, 4169-007 Porto, Portugal

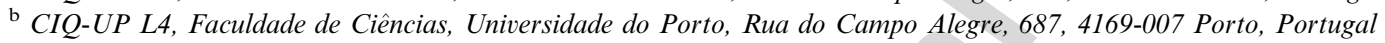 \\ ${ }^{\mathrm{c}}$ Instituto Superior de Ciências da Saúde-Norte, 4535-116 Gandra-Paredes, Portugal

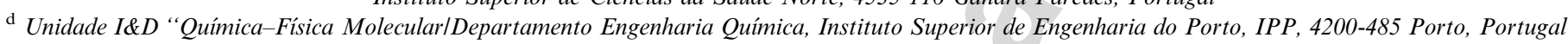 \\ e Unidade I\&D "Química-Física Molecular/Departamento Química Orgânica, Faculdade de Farmácia, Universidade do Porto, 4050-047 Porto, Portugal \\ ${ }^{\mathrm{f}}$ Department of Physiology, University of Saarland, D-66421 Homburg, Germany \\ ${ }^{g}$ Department of Chemistry, Faculty of Chemistry and Pharmacy, Central University of Las Villas, Santa Clara, 54830 Villa Clara, Cuba \\ ${ }^{\mathrm{h}}$ Department of Drug Design, Chemical Bioactive Center, Central University of Las Villas, Santa Clara, 54830 Villa Clara, Cuba \\ i Polyclinic ALTEA, Prilep, Macedonia \\ j Department of Chemistry, Faculty of Natural Sciences and Mathematics, Skopje, Macedonia
}

Received 27 September 2006

Available online 27 November 2006

\begin{abstract}
For the first time, the partition coefficients of the ionized forms of several opioids, amphetamine-like drugs, and their metabolites were determined by studying their ionic transfer process across the bare interface water|organic solvent. The ionic partition coefficients of the monocationic forms of 12 compounds-heroin, 6-monoacetylmorphine (6-MAM), morphine, acetylcodeine, codeine, dihydrocodeine, methamphetamine, amphetamine, 3,4-methylenedioxymethamphetamine (MDMA or "ecstasy"), 3,4-methylenedioxyamphetamine (MDA), 3-methoxy- $\alpha$-methyldopamine (3-OMe- $\alpha$-MeDA), and $\alpha$-methyldopamine ( $\alpha$-MeDA) - were attained using electrochemical measurements, by cyclic voltammetry, at the interface between two immiscible electrolyte solutions (ITIES). Then the acquired lipophilicity values were correlated to the chemical structure of the compounds and with the metabolic pathways central to each class of drugs. Although the mechanisms of biotoxicity of this type of drugs are still unclear, the data obtained evidence that the lipophilicity of metabolites may be a contributing factor for the qualitative differences found in their activity. In addition, the partition coefficients of the ionic drugs were calculated using three available software packages: ModesLab, Dragon, and HyperChem. As shown by cross-comparison of the experimental and calculated values, HyperChem was the most reliable software for achieving the main goal. The data obtained so far seem to be correlated to the proposed metabolic pathways of the drugs and could be of great value in understanding their pharmacological and/or toxicological profiles at the molecular level. This study may also contribute to gaining an insight into the mechanisms of biotransportation of this type of compounds given that the ionic partition coefficients reflect their ability to cross the membrane barriers. (C) 2006 Elsevier Inc. All rights reserved.
\end{abstract}

Keywords: Opioids; Amphetamine-like drugs; Metabolites; Partition coefficients; Ion transfer; Liquid|liquid interface

\footnotetext{
* Corresponding authors.

E-mail addresses: rgulaboski@fc.up.pt (R. Gulaboski),ncordeir@ fc.up.pt (M. N. D. S. Cordeiro).
}

The concept of hydrophobicity or lipophilicity takes on an important meaning in medicinal chemistry and molecular toxicology because of its remarkable significance in health sciences. Lipophilicity is one of the most important 
driving forces sustaining the passive transport of drugs through biomembranes, and it is a key factor in drugreceptor interactions [1-5].

The processes of biodistribution, protein binding, and metabolism of the drugs are generally dynamic and interdependent and can interplay and influence each other, being strictly related with lipophilicity. Actually, the study of drugs' ability to interact with membranes and enzymes is of the utmost importance for a proper understanding of their biological effects or side effects and disposition in the body [6]. In fact, lipophilicity correlates positively with high protein binding and with enzyme selectivity [5,7]. It should also be stressed that lipophilic compounds are the preferred targets for biotransformation and that nonspecific toxicity is expected to correlate with a compound's propensity to accumulate in cell membranes and consequently with its lipophilicity [5].

The techniques for the determination of oil-water partition coefficients in general, and of octanol-water partition coefficient in particular, are widely used to evaluate the lipophilicity of compounds [1-5]. The latter is one of the most commonly reported molecular descriptors of neutral drugs and is the one used most often to establish quantitative structure-activity relationships (QSARs), ${ }^{1}$ quantitative structure-toxicity relationships (QSTRs), and structuremetabolism relationships (QSMRs) [5]. However, there currently is a strong need for a more accurate evaluation of the partition coefficients not only of neutral forms but also of ionic molecules because more than $70 \%$ of both therapeutically and nontherapeutically used drugs are ionizable under physiological conditions [1,5]. It is worthwhile to notice that for a long time the importance of the lipophilicity of ionizable drugs and solutes has been underestimated, due mainly to the lack of reliable methods to determine the partition coefficients of the ionic forms. Even though it has been conventionally accepted that ionizable compounds cross membranes only in their neutral form or as ion pairs $[1,3,5]$, recent studies have shown a significant "passive" partition of ionic organic compounds, namely zwitterions [5,8-10]. Therefore, studies on the lipophilicity of ionizable drugs could lead to a better understanding of drug bioactivity and distribution, thereby helping to recognize their chemical and/or biological roles.

Although the determination of the partition coefficients of neutral solutes can be realized by various partitioning techniques, such as chromatography and simple shake flask

\footnotetext{
${ }^{1}$ Abbreviations used: QSAR, quantitative structure-activity relationship; QSTR, quantitative structure-toxicity relationship; QSMR, structure-metabolism relationship; ITIES, interface between two immiscible electrolyte solutions; 6-MAM, 6-monoacetylmorphine; MDA, 3,4-methylenedioxyamphetamine; MDMA, 3,4-methylenedioxymethamphetamine; $\alpha$-MeDA, $\alpha$-methyldopamine; 3-OMe- $\alpha$-MeDA, 3-methoxy- $\alpha$-methyldopamine; HPLC, high-performance liquid chromatography; DAD, diode array detector; DCE, 1,2-dichloroethane; LiCl, lithium chloride; TOATPB, tetraoctylammonium tetraphenylborate; NaTPB, sodium tetraphenylborate; BBB, blood-brain barrier; ADMET, absorption, distribution, metabolism, excretion, and toxicity.
}

methods [1,3-5], only the four-electrode voltammetry at the interface between two immiscible electrolyte solutions (ITIES) [3] and the recently developed three-phase electrode [2,11-15] are techniques capable of determining the partition coefficients of ionic solutes. Actually, during past decades the ion transfer across the ITIES has been studied extensively by means of several electrochemical and optical techniques [1-5]. Electrochemical experiments performed at polarizable ITIES are particularly suitable because they provide precise measurements of the Galvani potential difference.

In this work, attention is focused on the determination of partition coefficients of the ionic forms of opioids, amphetamine-like drugs, and some of their metabolites and analogues (Fig. 1) by using the four-electrode voltammetry at the ITIES. The increase of chemical and biological studies on this type of drugs has been motivated by its toxicological public health significance in the hope for a better understanding of its biological behavior at the molecular level. The importance of the partition coefficient evaluation of this type of drugs and metabolites is evident in previously published works [16-21], and undoubtedly it could be related to the toxicity profile before or after biotransformation of the drugs and/or their metabolites and their capacity to cross membrane barriers.

For the sake of getting a better insight into the membrane transfer characteristics of ionic drugs, a rapid and reliable electrochemical method was designed and applied to the determination of $\log P$ values of the ionic forms of this type of chemical drugs. In addition, the experimental values were compared with the estimated partition coefficients, calculated by using different software packages-ModesLab, Dragon, and HyperChem [22] - and, when available, with reference literature values [23-25].

\section{Materials and methods}

\section{Chemicals}

Morphine, codeine, and amphetamine were obtained from Uquipa and Sigma (Lisbon, Portugal) as their hydrochloride salts and were used without further purification. Dihydrocodeine bitartrate was kindly provided by Knoll Lusitana (Prior Velho, Portugal).

Acetylcodeine, heroin, 6-monoacetylmorphine (6-MAM), methamphetamine, 3,4-methylenedioxyamphetamine (MDA), 3,4-methylenedioxymethamphetamine (MDMA or "ecstasy"), $\alpha$-methyldopamine ( $\alpha$-MeDA) and 3-methoxy- $\alpha$ methyldopamine (3-OMe- $\alpha-\mathrm{MeDA})$ were synthesized as described elsewhere [26-28].

\section{Purity determination}

The purity of the final products $(>97 \%)$ was verified using two different high-performance liquid chromatography (HPLC) systems: one equipped with a UV detector 

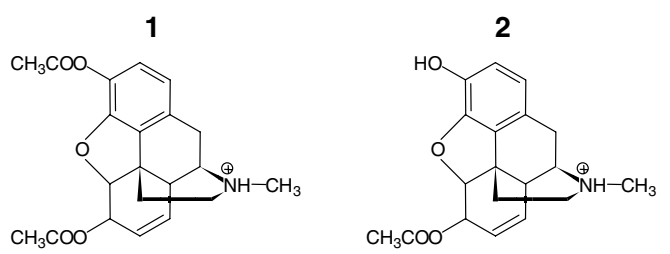

3
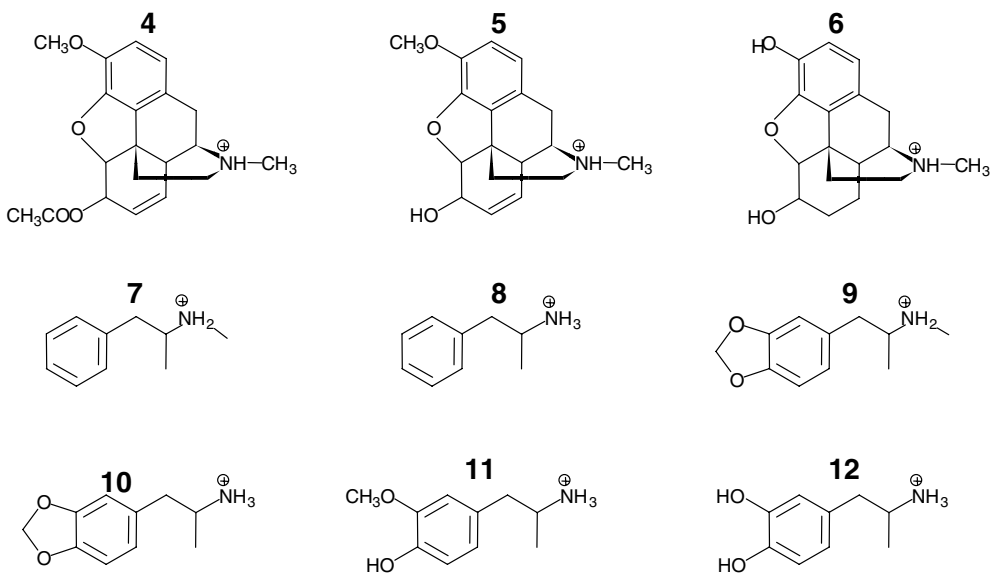

Fig. 1. Chemical structures of the studied compounds: heroin (1), 6-MAM (2), morphine (3), acetylcodeine (4), codeine (5), dihydrocodeine (6), methamphetamine (7), amphetamine (8), MDMA or ecstasy (9), MDA (10), 3-OMe- $\alpha$-MeDA (11), and $\alpha$-MeDA (12).

(diode array detector [DAD]) and the other with an electrochemical detector. Initially, the chromatograms were obtained in an HPLC-DAD system consisting of a Jasco instrument (pump model 880-PU and solvent mixing model 880-30, Tokyo, Japan) equipped with a commercially prepacked Nucleosil RP-18 analytical column $(250 \times 4.6 \mathrm{~mm}, 5 \mu \mathrm{m}$, Macherey-Nagel, Düren, Germany) and UV detection (Jasco model 875-UV) at the maximum wavelength determined by the analysis of the UV spectrum of each compound. The isocratic mobile phase consisted of $10 \mathrm{mM}$ aqueous ammonium acetate (adjusting the final $\mathrm{pH}$ to 3 with hydrochloric acid) with $10 \%$ acetonitrile at a flow rate of $1 \mathrm{ml} / \mathrm{min}$ at room temperature. The chromatographic data were processed with a Compaq computer fitted with CSW 1.7 software (DataApex, Czech Republic).

A Waters 2690 Alliance system equipped with a Concorde Electrochemical Detector (Waters, Milford, MA, USA) was also used. The electrochemical cell was a VT-03 flow cell (Antec Leyden, Zoeterwoude, Netherlands) with a confined wall jet design in a three-electrode configuration: a 2-mm diameter glassy carbon working electrode, an in situ $\mathrm{Ag} / \mathrm{AgCl}$ reference electrode, and a stainless-steel auxiliary electrode. The electrochemical detector was operated in oxidative amperometric mode with the working potentials between -100 and $+1200 \mathrm{mV}$. The HPLC separation was carried out in a reverse-phase LC-18-S Supelcosil analytical column $(150 \times 4.6 \mathrm{~mm}, 5 \mu \mathrm{m}$, Supelco, Bellefonte, PA, USA). As mobile phase, $100 \mathrm{mM}$ sodium acetate $(\mathrm{pH} 4.3) /$ methanol (10:3) was used in isocratic mode at a flow rate of $1 \mathrm{ml} / \mathrm{min}$. Chromatograms were acquired in a Millennium 32 Chromatography Manager (Waters).

\section{Electrochemical studies}

For the electrochemical measurements, the following chemicals were used as received: 1,2-dichloroethane (DCE, 99.9\%, Sigma), lithium chloride ( $\mathrm{LiCl}, 99 \%$, Aldrich), tetraoctylammonium tetraphenylborate (TOATPB), and sodium tetraphenylborate (NaTPB). Tetramethylammonium-TMN ${ }^{+}$and tetrabutylammonium-TButN were used as internal standards. MilliQ Plus water $(18 \mathrm{M} \Omega \mathrm{cm}$ ) was used for preparation of all aqueous solutions as well as for rinsing. All experiments were carried out at room temperature. The ITIES system consists of a four-electrode cell (Fig. 2) with a flat water|DCE interface having an area of $0.28 \mathrm{~cm}^{2}$ :

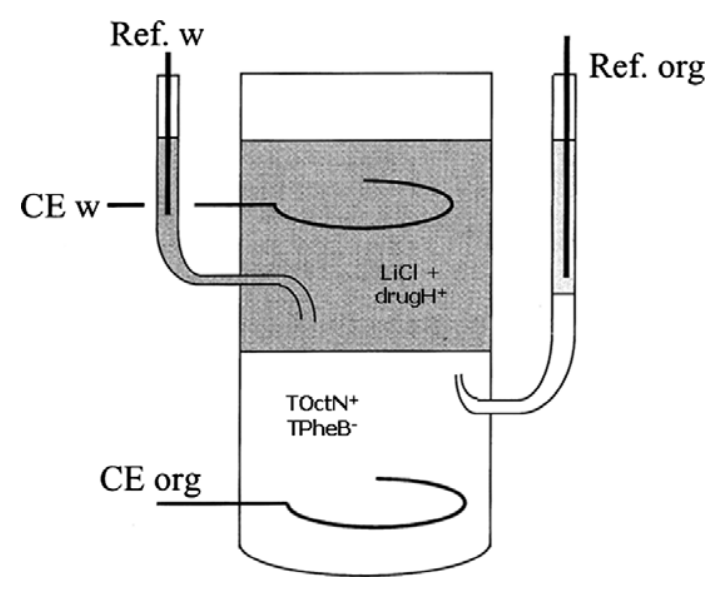

Fig. 2. Schematic representation of the electrochemical cell used in the experiments. The aqueous $(\mathrm{w})$ phase contained $\mathrm{LiCl}$ and the protonated form of the drug under study $\left(\mathrm{DrugH}^{+}\right)$, and the organic (org) phase contained tetraoctylammonium tetraphenylborate salt $\left(\mathrm{TOctN}^{+} \mathrm{TPheB}^{-}\right)$. CE, counter electrodes; Ref., reference electrodes. 


\section{$\mathrm{Ag} / \mathrm{AgCl} \mid 50 \mathrm{mM} \mathrm{NaTPB}+100 \mathrm{mM} \mathrm{LiCl}(\mathrm{w})$ \\ | $50 \mathrm{mM}$ TOATPB (DCE) \\ $\left|0.1 \mathrm{M} \mathrm{LiCl}+x \mathrm{mM} \mathrm{drug}^{+}(\mathrm{w})\right| \mathrm{AgCl} / \mathrm{Ag}$.}

The $\mathrm{pH}$ of the aqueous solutions was 6.8. Under these conditions, all of the studied compounds were present in the water solutions as monocations given that the $\mathrm{p} K_{\mathrm{H}+}$ values of all compounds range between 7.6 and 10.1 (see Table 2). The voltammetric measurements at ITIES were carried out by applying the cyclic staircase voltammetry with scan rates varying from 2 to $150 \mathrm{mV} / \mathrm{s}$. All voltammograms were measured using the Ohmic drop compensation mode.

\section{Theoretical studies}

Calculated/Predicted $\log P$ data were obtained with three different software packages-Modeslab, Dragon, and HyperChem-using either atom-based or different fragmental approaches [22].

\section{Rational background}

The partition coefficient of an ion $\mathrm{i}\left(\log P_{\mathrm{i}}\right)$ depends on the Galvani potential difference across the interface, as shown by the following equations:

$\log \left(P_{\mathrm{i}}\right)=-\frac{\Delta G_{\mathrm{i}}^{\theta^{\circ}}}{2.3 R T}+\frac{z_{\mathrm{i}} F}{2.3 R T} \Delta \varphi_{\mathrm{w}}^{\mathrm{o}}$

or

$\log \left(P_{\mathrm{i}}\right)=\log \left(P_{\mathrm{i}}^{\theta_{\mathrm{w}}^{\mathrm{o}}}\right)+\frac{z_{\mathrm{i}} F}{2.3 R T} \Delta \varphi_{\mathrm{w}}^{\mathrm{o}}$,

$\log \left(P_{\mathrm{i} \mathrm{w}}^{\theta^{\circ}}\right)=-\frac{\Delta G_{\mathrm{i} w}^{\theta^{\circ}}}{2.3 R T}$

where $\log \left(P_{\mathrm{i} \text { w }}^{\theta^{\circ}}\right)$ is the standard partition coefficient of the ionic solute (i) transferred from the water (w) into the organic (o) phase. In the above equations, $\Delta \varphi^{\circ}{ }_{w}$ is the Galvani potential difference between the water and the organic phase, and $\Delta G_{\mathrm{i} \text { w }}^{\theta^{\circ}}$ is the standard Gibbs energy of transfer of the ionic solute (i) from the water to the organic phase. $\Delta G_{\mathrm{i} \text { w }}^{\theta^{\circ}}$ [and consequently $\left.\log \left(P_{\mathrm{i} \text { w }}^{\theta^{\circ}}\right)\right]$ is directly related to the voltammetric half-wave potential of the ion transfer $\Delta \varphi_{\mathrm{iw}}^{1 / 2^{0}}$ Eq. (3). This latter parameter can be directly deduced from the voltammetric experiments using wellestablished procedures $[1,3-5]$. It is worth noting that cyclic $[1,3,5]$ and square-wave voltammetry $[2,3]$ at the ITIES are particularly appropriate techniques for the experimental determination of the standard partition coefficients of ionic solutes $\left[\log \left(P_{\mathrm{iw}}^{\theta^{\circ}}\right)\right]$ due to the possible use of an external control of the interfacial potential and hence of the ionic distribution between the two adjacent phases.

$n$-Octanol traditionally has been regarded as the reference organic solvent for the lipophilicity studies of neutral solutes because of its amphiphatic structural properties that are thought to be similar to the phospholipids present in biomembranes [5,29]. Although developed recently, the three-phase electrode technique has proven to be a successful tool for the evaluation of the standard partition coefficients of anions at the water| $\mid n$-octanol interface $[2,15]$. Unfortunately, due to the inaccessibility to the redox probe capable of probing cation transfer across water $\mid n$-octanol interface when using the three-phase electrode [14a], we were restricted in using this technique in our experiments. However, $n$-octanol cannot be used as an organic medium for assessing the lipophilicity data of ions by voltammetry at the ITIES due to the nonpolarizable nature of the interface with water [1-5]. This methodology has been applied to the study of cation transfer using DCE as solvent, which usually is noted as a good alternative for $n$-octanol $[3-5,30$ 33], although both solvents have a different nature. A schematic representation of the electrochemical cell used in the current work is depicted in Fig. 2.

The ion transfer of the monocationic forms of the studied compounds was studied by using cyclic voltammetry (see representative voltammograms in Fig. 3), whereas the most relevant thermodynamic parameters of lipophilicity of the investigated compounds are given in Table 1. The peak-to-peak separation between the peaks at more negative potentials (corresponding to the transfer of the cations from water to DCE) and peaks at more positive potentials (portraying the transfer of the cations from DCE to water) was approximately $60 \mathrm{mV}$ in all cases and did not vary significantly with the scan rate. It is worth mentioning that in some cases the peak-to-peak separation was slightly more than $65 \mathrm{mV}$, probably due to the slower kinetics of cation transfer across the liquid|liquid interface. This effect, however, does not affect the thermodynamic data given in Table 1. Moreover, the peak currents of both positive and negative peaks were proportional to the square root of the imposed scan rates and to the concentration of the compounds present in the initial aqueous solutions. The main features of the cyclovoltammetric responses as a function of the applied scan rate are given in Table 2. All of these features imply an electrochemically reversible and diffusion-controlled ion transfer of all the compounds under study $[1,3,5]$. These experimental conditions enabled

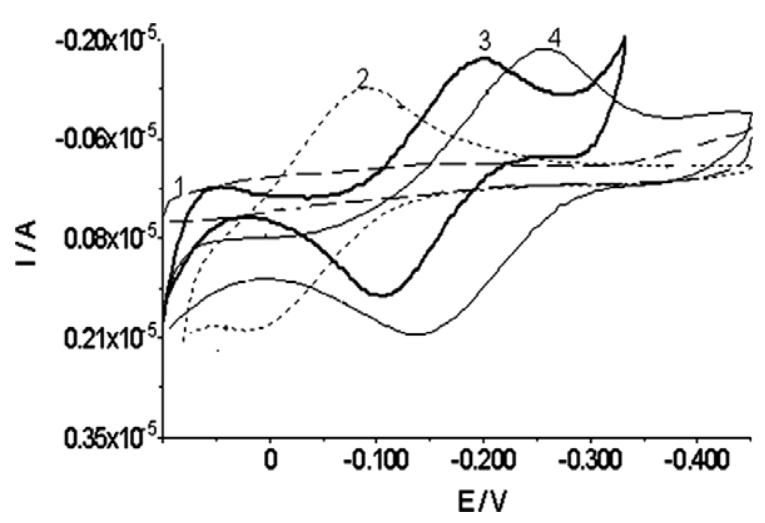

Fig. 3. Representative cyclic voltammograms of the compounds: blank (curve 1), heroin (curve 2), codeine (curve 3), and morphine (curve 4). The scan rate was $25 \mathrm{mV} / \mathrm{s}$, and the concentration of the compounds was $0.25 \mathrm{mmol} / \mathrm{L}$. 
Table 1

Partition coefficient values of the drugs under study and metabolites

\begin{tabular}{|c|c|c|c|c|}
\hline Compound & $\begin{array}{l}\log P_{\mathrm{w}}^{n-\text { oct }} \text { (of neutral molecules) } \\
\text { (from literature) }^{\mathrm{a}, \mathrm{b}, \mathrm{c}}\end{array}$ & $\begin{array}{l}\log P_{\mathrm{w}}^{n-\text { oct }}(\text { calculated for } \\
\text { neutral forms })^{\mathrm{d}}\end{array}$ & $\begin{array}{l}\log P_{\mathrm{w}}^{n-o c t} \text { (calculated for } \\
\text { cationic forms) }\end{array}$ & $\begin{array}{l}\log P_{\mathrm{w}}^{\mathrm{DCE}} \text { (experimental for } \\
\text { cationic forms) }\end{array}$ \\
\hline Heroin (1) & $1.58^{\mathrm{a}, \mathrm{b}, \mathrm{c}}\left(\right.$ octanol $\left./ \mathrm{H}_{2} \mathrm{O}\right)$ & 1.69 & -1.83 & -0.58 \\
\hline 6-MAM (2) & $1.55^{\mathrm{c}}$ & 1.50 & -1.62 & -2.45 \\
\hline Morphine (3) & $-0.10^{\mathrm{a}, \mathrm{b}}($ octanol $/ \mathrm{pH} 7.4)+0.89^{\mathrm{c}}$ & 0.76 & -1.75 & -4.55 \\
\hline Acetylcodeine (4) & n.f. & 1.82 & -1.58 & -1.55 \\
\hline Codeine (5) & $0.60^{\mathrm{a}, \mathrm{b}}($ octanol $/ \mathrm{pH} 7.4)+1.19^{\mathrm{c}}$ & 1.08 & -1.71 & -2.00 \\
\hline Dihydrocodeine (6) & $-1.50^{\mathrm{a}, \mathrm{b}}(\mathrm{ether} / \mathrm{pH} 7.0)$ & 1.33 & -1.01 & -3.95 \\
\hline Methamphetamine (7) & $2.10^{\mathrm{a}, \mathrm{b}}\left(\right.$ octanol $\left./ \mathrm{H}_{2} \mathrm{O}\right)$ & 1.79 & 0.87 & -2.03 \\
\hline Amphetamine $(\mathbf{8})$ & $1.80^{\mathrm{a}, \mathrm{b}}\left(\right.$ octanol $\left./ \mathrm{H}_{2} \mathrm{O}\right)$ & 1.76 & 0.62 & -2.52 \\
\hline Ecstasy (MDMA) (9) & n.f. & 1.76 & -0.93 & -3.22 \\
\hline MDA (10) & $1.64^{\mathrm{a}, \mathrm{b}}\left(\mathrm{octanol} / \mathrm{H}_{2} \mathrm{O}\right)$ & 1.79 & -1.18 & -3.55 \\
\hline 3-OMe- $\alpha-\mathrm{MeDA}(\mathbf{1 1})$ & n.f. & 2.04 & -1.40 & -1.83 \\
\hline$\alpha-\operatorname{MeDA}(12)$ & n.f. & 0.95 & -1.43 & -3.82 \\
\hline
\end{tabular}

Note. n.f., not found

a Ref. [23].

b Ref. [24].

c Ref. [25].

d Calculated according to HyperChem.

Table 2

Equation of the linear regression line, correlation coefficient corresponding to the linear line, and peak-to-peak separation as a function of applied scan rates

\begin{tabular}{|c|c|c|c|c|c|}
\hline Compound & $\begin{array}{l}\text { Range of } \\
\text { applied scan } \\
\text { rates }\left(v / \mathrm{mV} \mathrm{s}^{-1}\right)\end{array}$ & $\begin{array}{l}\text { Equation of linear line } \\
\left(I_{\mathrm{p}, \mathrm{a}} / \mu \mathrm{A}=a v^{0.5}+b\right)\end{array}$ & $\begin{array}{l}\text { Correlation } \\
\text { coefficient of linear } \\
\text { regression }\left(R^{2}\right)\end{array}$ & $\begin{array}{l}\text { Range of } \\
\text { peak-to-peak separation } \\
\left(\Delta E_{\mathrm{p}} / \mathrm{mV}\right)\end{array}$ & $\begin{array}{l}\text { Protonation } \\
\text { constant }\left(\mathrm{p} K_{\mathrm{H}}^{+}\right)\end{array}$ \\
\hline 1 & $2-150$ & $=1.20 v^{0.5}-2.17$ & 0.99 & $60-72$ & $7.60\left(23^{\circ} \mathrm{C}\right)$ \\
\hline 2 & $2-150$ & $=1.25 v^{0.5}-1.98$ & 0.99 & $58-64$ & $8.00\left(25^{\circ} \mathrm{C}\right)$ \\
\hline 3 & $2-150$ & $=1.47 v^{0.5}-2.05$ & 0.98 & $62-72$ & $9.90\left(20^{\circ} \mathrm{C}\right)$ \\
\hline 4 & $2-150$ & $=1.35 v^{0.5}-1.89$ & 0.98 & $60-68$ & $9.04\left(25^{\circ} \mathrm{C}\right)$ \\
\hline 5 & $2-150$ & $=1.24 v^{0.5}-1.46$ & 0.99 & $56-66$ & $8.20\left(20^{\circ} \mathrm{C}\right)$ \\
\hline 6 & $2-150$ & $=1.60 v^{0.5}-1.62$ & 0.98 & $64-75$ & $8.80\left(25^{\circ} \mathrm{C}\right)$ \\
\hline 7 & $2-150$ & $=1.42 v^{0.5}-1.94$ & 0.99 & $58-64$ & $10.1\left(25^{\circ} \mathrm{C}\right)$ \\
\hline 8 & $2-150$ & $=1.26 v^{0.5}-2.02$ & 0.97 & $56-65$ & $10.1\left(25^{\circ} \mathrm{C}\right)$ \\
\hline 9 & $2-150$ & $=1.04 v^{0.5}-1.14$ & 0.99 & $58-63$ & $9.20\left(25^{\circ} \mathrm{C}\right)$ \\
\hline 10 & $2-150$ & $=1.18 v^{0.5}-1.27$ & 0.98 & $56-64$ & $9.67\left(25^{\circ} \mathrm{C}\right)$ \\
\hline 11 & $2-150$ & $=1.38 v^{0.5}-1.92$ & 0.98 & $60-70$ & $9.80\left(25^{\circ} \mathrm{C}\right)$ \\
\hline 12 & $2-150$ & $=1.23 v^{0.5}-1.80$ & 0.99 & $60-68$ & $9.14\left(25^{\circ} \mathrm{C}\right)$ \\
\hline
\end{tabular}

Note. The concentration of the investigated compounds in the aqueous solution was $0.25 \mathrm{mmol} / \mathrm{L}$. The last column refers to the values of the protonation constants $\mathrm{pK}_{\mathrm{H}}^{+}$of the investigated compounds at given temperatures.

the use of the half-peak potentials for the determination of the standard Gibbs transfer energies and $\log P$ values of the monoprotonated forms of the studied compounds. This was carried out by applying Eq. (3) and the relationship between the standard Gibbs energy of ion transfer and the standard potential of ion transfer $\left(\Delta \varphi_{\mathrm{i}}^{\theta_{\mathrm{w}}^{\circ}}\right)$, that is,

$\Delta \varphi_{\mathrm{i} \text { w }}^{\theta^{\mathrm{o}}}=-\frac{\Delta G_{\mathrm{i} \mathrm{w}}^{\theta^{\mathrm{o}}}}{z_{\mathrm{i}} F}$.

It is important to note that the standard potential values $\left(\Delta \varphi_{\mathrm{i}}^{\theta_{\mathrm{w}}^{\circ}}\right)$ of the ion transfer of the compounds were determined from the differences between the half-peak potential of the cyclic voltammograms of single compounds and the half-peak potential of internal standards with known values of the $\Delta \varphi_{\mathrm{i}}^{\theta_{\mathrm{w}}^{\circ}}$ (i.e., tetramethylammonium-TMetN ${ }^{+}$ or tetrabutylammonium-TButN $\left.{ }^{+}\right)$that have been added in the voltammetric cell $\left(\Delta \varphi_{\mathrm{TMetN}^{+}{ }_{\mathrm{w}}}^{{ }^{\mathrm{DCE}}}=-0.160 \mathrm{~V}\right.$ and
$\left.\Delta \varphi_{\mathrm{TButN}^{+} \mathrm{w}}^{\theta^{\mathrm{DCE}}}=+0.164 \mathrm{~V}[3]\right)$. All of the relevant thermodynamic parameters concerning the lipophilicity of the ionic forms of the studied compounds, together with the experimental and estimated partition coefficients of neutral drug forms, are depicted in Table 1.

\section{Results and discussion}

Drug metabolism is largely the biological process responsible for degradation of lipophilic drugs. The most relevant mechanism is their enzymatic conversion to more polar products, which have the propensity to be excreted relatively more rapidly. In general, the enzymes catalyze the biotransformation of the drugs by the following general reactions: oxidation, reduction, hydrolysis, deamination (phase I reactions), and conjugation (sulfation, glucuronation, methylation, acetylation - phase II reactions). The 
phase I reactions correspond to the conversion of the hydrophobic moieties to more hydrophilic compounds. In this perspective, all reactions of xenobiotic metabolism should yield metabolites of increased polarity relative to the parent compounds. This rule often, but not always, is verified because a noticeable number of xenobiotics and metabolites fortuitously resemble endogenous compounds and become substrates of endobiotic-metabolizing pathways yielding products of increased lipophilicity. Some examples include: mono- $O$-methylation of catechols, $\mathrm{N}$-acetylation of primary amines (rare), and esterification of some alcohols with fatty acids [34].

Actually, many in vivo metabolic studies have demonstrated a dependence of biotransformation on lipophilicity, suggesting that a predominant role for transport and partitioning processes is the determination of partition coefficients for either the ionized forms of several metabolites or the parent compounds - a relevant tool to corroborate this type of information.

So, in this work, the lipophilic properties of the following compounds (Table 1) were determined: heroin, 6-MAM, morphine, acetylcodeine, codeine, dihydrocodeine, methamphetamine, amphetamine, MDA, 3-OMe- $\alpha$-MeDA, and $\alpha$-MeDA. To perform a comparative analysis of the data, the drugs were divided into four subgroups.

The lipophilicity of the cationic forms of the drugs of the first subgroup (the structurally related opioids: heroin (1), 6-MAM (2), and morphine (3)) decreases progressively from diacetylated compound to morphine. The lipophilicity of heroin (diacetylmorphine) is found to be higher than that of morphine by nearly $4 \log P$ units. Accordingly, the phase I metabolite 6-MAM is shown to be less lipophilic than heroin (by $\sim 2 \log P$ units), proving that in this metabolic process a typical detoxification pathway occurs. These results are in agreement with previous findings that heroin molecules can pass through the blood-brain barrier (BBB) much faster than the drug's metabolite morphine [35]. This phenomenon frequently contributes to a more intense pharmacodynamic effect of heroin compared with morphine [36]. It could be stressed that the ionic form of heroin possesses physicochemical features to surpass BBB given that it is possible in this work to propose a different magnitude of $\log P$ values for the cationic forms similar to that established by Hansch and coworkers, finding that the ideal lipophilicity of neutral compounds for passive penetration into the brain is approximately $2\left(\log P_{\text {oct }}\right.$ scale) [37,38].

Moving on to the second subgroup (acetylcodeine (4), codeine (5), and dihydrocodeine (6)), one can see that the lipophilicity of the hydrogenated codeine (i.e., dihydrocodeine) is much lower (by nearly $2 \log P$ units) than the corresponding lipophilicity of codeine. The effect of increased hydrophilicity by the addition of two hydrogen atoms to the unsaturated double bond in the cyclic system of codeine can be assigned to its role in forming additional hydrogen bonds with water molecules. This leads to an increase of the hydration energy of the hydrogenated compound, consequently leading to a higher hydrophilicity [5]. The partition coefficient data obtained for the ionic forms of acetylcodeine versus codeine are in accordance with a phase I metabolic process. The esterification of the hydroxyl group of codeine with an acetyl group brings higher lipophilicity to the final product (acetylcodeine), an effect that has been described previously for acetylmorphine derivatives. In addition, it should be noted that the methylation of the hydroxyl group of morphine led to a more lipophilic compound (codeine) (Table 1), a fact showing the feasibility of the experimental determinations.

The third subgroup of compounds studied (Table 1) consists of methamphetamine (7) and its metabolite amphetamine (8). The methylation of the $\mathrm{NH}_{3}{ }^{+}$group of amphetamine increases the lipophilicity of the drug by approximately $0.5 \log P$ units. This lipophilic contribution of the $\mathrm{CH}_{3}$ group to the overall lipophilicity of the compound is in the same range as what has been found and described previously in the literature [14c].

In what is considered to be the "designer drug" ecstasy (9, MDMA) and its metabolites, it was concluded that the outcome of the increase of the lipophilicity of ionized metamphetamine in relation to amphetamine can also be noticed by comparing the $\log P$ of the drug and the metabolite MDA (10). That is, the ionic form of ecstasy possesses a higher lipophilicity than its metabolite/precursor (MDA), which is itself a drug of abuse.

The lipophilicity determined for ionic forms of the two ecstasy metabolites, 3-OMe- $\alpha$-MeDA (11) and $\alpha$-MeDA (12), are in agreement with the expectations, with $\alpha$-MeDA showing lower lipophilicity than 3-OMe- $\alpha-\mathrm{MeDA}$. These results help us to understand the previously published data [28], where it was found that in the metabolism of MDMA both $N$-methylation and $O$-methylation of the catecholamine-type compounds enhance cytotoxicity. Although data on the biotransformation of this type of drugs are limited, a few studies on the metabolism of $N$-alkylated amphetamines showed that both $N$-dealkylation and ring hydroxylation pathways can occur, whereas ring oxidative metabolic pathway is more extensive [28]. From these data, it is apparent that $N$-dealkylated amphetamines have higher lipophilicity than do the hydroxylated ones, giving one reason for the difference found in the extension of the metabolic pathways.

In addition, because drugs' lipophilicity is strongly correlated with their pharmacological and toxicological properties, an effort was made to check the mathematical models that are capable of accurately predicting their value either for these drugs or for new drug candidates. Several software packages have been used to calculate the partition coefficients of the neutral and cationic forms of the studied drugs. The cross-comparison of the experimental and calculated values reveals that no good linear correlation was found with the experimental data obtained. One of the reasons for this certainly is the different nature of the organic solvent used (DCE) and $n$-octanol, which is a standard organic solvent in all software packages for $\log P$ 
calculations. Another reason could be the fact that all software packages are based on the so-called additive lipophilic contribution methods of groups or fragments and do not take into account important lipophilic effects such as charge delocalization, iceberg effects, and cavity formation energy $[1,5]$. This means that one always should interpret with caution the data estimated theoretically with most of the commercial packages available. Nevertheless, we should point out that HyperChem gave the best correlation, indicating a superiority of the atom-based method over fragmental methods for this particular set of ionic drugs.

It is important to note that the partition coefficient algorithms obtained so far could be applied in the future, for instance, in the development of membrane transport models [39]. This could also be important for future absorption, distribution, metabolism, excretion, and toxicity (ADMET) studies as well as QSMR studies [5].

\section{Conclusions}

Lipophilicity and hydrogen-bonding ability are considered to be the most important physicochemical properties that rule the transmembrane movement of the drugs, whether used therapeutically or not $[1,5]$. These parameters are also related to the affinity of the solute for the hydrophobic bilayer and its ability to leave the favorable hydrogen-bonding environment of the aqueous phase. Although initially it was thought that only neutral compounds were able to diffuse through biological membranes, recent studies have shown that transmembrane diffusion of ions does occur. Because most parts of drugs behave as weak acids or bases, they are predisposed to be ionized at physiological pH [5]. The current work examined the transferring features of the ionic forms of several opioids and amphetamine-like drugs and their metabolites by using four-electrode voltammetry at the ITIES, revealing their ability (or not) to cross membranes. The obtained lipophilicity of the ionic forms of these drugs, expressed via their partition coefficients, was related to the chemical structures of the compounds and the biotoxicity. The great advantage of the technique employed is the possibility of evaluating the $\log P$ of charged molecules by employing a method that is not time- or material-consuming.

In addition, it was found that the software package HyperChem gave the best correlation, indicating a superiority of the atom-based method over fragmental methods for this particular set of ionic drugs. The data of this study are considered to be a contribution for a better understanding of some toxicological and/or pharmacological features of these drugs given that lipophilicity is found to be a major determinant of pharmacodynamic and pharmacokinetic properties of drugs. Therefore, it is consensual that knowledge of both the metabolic pathways and the physicochemical properties of the drugs is believed to be critical for understanding their biological role.
Future work will be extended to other phase I metabolites and to the products of the phase II detoxification process, namely the compounds originated by glycoside, sulfate, and glutathione conjugation. In addition, a more comprehensive study currently being developed will consider the modification of the liquid|liquid interface with phospholipids [32], mimicking in that way the double-layer living cell membranes.

\section{Acknowledgments}

This work was supported by Portuguese Fundação para a Ciência e a Tecnologia (FCT) (projects POCTI/QUI/ 4XXX/2001, POCTI/QUI/41074/2001, and POCI/SAUFCF/58330/2004). Rubin Gulaboski acknowledges the FCT of Portugal for the postdoctoral fellowship grant SFRH/BPD/14894/2004.

\section{References}

[1] A.G. Volkov, Liquid Interfaces in Chemical, Biological, and Pharmaceutical Applications, Marcel Dekker, New York, 2001.

[2] F. Scholz, U. Schröder, R. Gulaboski, Electrochemistry of Immobilized Particles and Droplets, Springer, Berlin, 2005.

[3] H.H. Girault, D.J. Schiffrin, Electrochemistry of liquid-liquid interfaces, in: A.J. Bard (Ed.), Electroanalytical Chemistry: A Series of Advances, vol. 15, Marcel Dekker, New York, 1989, pp. 1-132.

[4] J. Koryta, P. Vanysek, in: H. Gerisher, C.W. Tobias (Eds.), Advances in Electrochemistry and Electrochemical Engineering, vol. 12, John, New York, 1996, pp. 113-130.

[5] B. Testa, H. van de Waterbeemd, G. Folkers, R. Gay, Pharmacokinetic Optimization in Drug Research, Wiley-WCH, Weinheim, Germany, 2001.

[6] O.A. Raevsky, Physicochemical descriptors in property-based drug design, Med. Chem. 4 (2004) 1041-1052.

[7] D.F.V. Lewis, M.N. Jacobs, M. Dickins, Compound lipophilicity for substrate binding to human P450s in drug metabolism, Drug Disc. Today 9 (2004) 530-536.

[8] F. Reymond, D. Fermin, H. Lee, H. Girault, Electrochemistry at liquid/liquid interfaces: methodology and potential applications, Electrochim. Acta 45 (2000) 2647-2662.

[9] S.L. Price, J.S. Andrews, C.W. Murray, R.D. Amos, The effect of basis set and electron correlation on the predicted electrostatic interactions of peptides, J. Am. Chem. Soc. 114 (1992) 8268-8276.

[10] C.J. Alcorn, R.J. Simpson, D.E. Leahy, T.J. Peters, Partition and distribution coefficients of solutes and drugs in brush-border membrane-vesicles, Biochem. Pharmacol. 45 (1993) 1775-1782.

[11] F. Scholz, R. Gulaboski, Determining the Gibbs energy of ion transfer across water-organic liquid interfaces with three-phase electrodes, ChemPhysChem 6 (2005) 16-28.

[12] R. Gulaboski, A. Galland, G. Bouchard, K. Caban, A. Kretschmer, P.-A. Carrupt, Z. Stojek, H.H. Girault, F. Scholz, A comparison of the solvation properties of 2-nitrophenyloctyl ether, nitrobenzene, and $n$-octanol as assessed by ion transfer experiments, J. Phys. Chem. B 108 (2004) 4565-4572.

[13] R. Gulaboski, F. Scholz, Lipophilicity of peptide anions: an experimental data set for lipophilicity calculations, J. Phys. Chem. B 107 (2003) 5650-5657.

[14] (a) F. Quentel, V. Mirceski, M. L'Her, Lutetium bis(tetra-tertbutylphthalocyaninato): a superior redox probe to study the transfer of anions and cations across the waternitrobenzene interface by means of square-wave voltammetry at the three-phase electrode, J. Phys. Chem. B 109 (2005) 1262-1267;

(b) S. Komorsky-Lovric, K. Riedl, R. Gulaboski, V. Mirceski, 
Scholz, Determination of standard Gibbs energies of transfer of organic anions across the water/nitrobenzene interface, Langmuir 18 (2002) 8000-8005;

(c) R. Gulaboski, K. Riedl, F. Scholz, Standard Gibbs energies of transfer of halogenate and pseudohalogenate ions, halogen substituted acetates, and cycloalkyl carboxylate anions at the water|nitrobenzene interface, Phys. Chem. Chem. Phys. 5 (2003) 1284-1289.

[15] R. Gulaboski, V. Mirceski, F. Scholz, An electrochemical method for determination of the standard Gibbs energy of anion transfer between water and $n$-octanol, Electrochem. Commun. 4 (2002) 277-283.

[16] M. Carvalho, F. Remiao, N. Milhazes, F. Borges, E. Fernandes, M.C. Monteiro, M.J. Gonçalves, V. Seabra, F. Amado, F. Carvalho, M.L. Bastos, Metabolism is required for the expression of ecstasy-induced cardiotoxicity in vitro, Chem. Res. Toxicol. 17 (2004) 623-632.

[17] M. Carvalho, F. Remiao, N. Milhazes, F. Borges, E. Fernandes, F. Carvalho, M.L. Bastos, The toxicity of $n$-methyl- $\alpha$-methyldopamine to freshly isolated rat hepatocytes is prevented by ascorbic acid and $N$-acetylcysteine, Toxicology 200 (2004) 193-203.

[18] M. Carvalho, F. Remiao, N. Milhazes, F. Borges, E. Fernandes, F. Carvalho, M.L. Bastos, In vitro hepatotoxicity of $N$-methyl- $\alpha-$ methyldopamine: protective effect by antioxidants, Toxicol. Appl. Pharmacol. 197 (2004) 333-334.

[19] M. Carvalho, G. Hawsworth, N. Milhazes, F. Borges, T.J. Monks, E. Fernandes, F. Carvalho, M.L. Bastos, Role of metabolites in MDA (ecstasy) induced nephrotoxicity: An in vitro study using rat and human renal proximal tubular cells, Arch. Toxicol. 76 (2002) $581-588$.

[20] J.M.P.J. Garrido, C. Delerue-Matos, F. Borges, T.R.A. Macedo, A.M. Oliveira-Brett, Electrochemical analysis of opiates: an overview, Anal. Lett. 37 (2004) 831-844.

[21] A.K. Ghose, A. Pritchett, G.M. Crippen, Atomic physicochemical parameters for 3-dimensional structure directed quantitative structure-activity relationships: modeling hydrophobic interactions, J. Comput. Chem. 9 (1988) 80-90.

[22] (a) Y. Gutierrez, E. Estrada, MODESLAB 1.0 (Molecular Descriptors Laboratory) for Windows, Universidad de Santiago de Compostela, Spain, 2002.;

(b) R. Todeschini, V. Consonni, M. Pavan, Dragon software, version 2.1, 2002.

[23] A.C. Moffat, M.D. Osselton, B. Widdop, L.Y. Galichet, Clarke's Analysis of Drugs and Poisons, 3rd ed., Pharmaceutical Press, London, 2004.

[24] A.C. Moffat, Clarke's Isolation and Identification of Drugs, 2nd ed., Pharmaceutical Press, London, 1986.

[25] A. Avdeef, D.A. Barret, P.N. Shaw, R.D. Knaggs, S.S. Davis, $\mathrm{pH}-$ Metric $\log \mathrm{P}$.7. Octanol, chloroform, and propylene glycol dipelargonate-water partitioning of morphine-6-glucoronide and other related opiates, J. Med. Chem. 39 (1996) 4377-4381.
[26] J.M.P.J. Garrido, C. Delerue-Matos, F. Borges, T.R.A. Macedo, A.M. Oliveira-Brett, Voltammetric oxidation of drugs of abuse: II. Codeine and metabolites, Electroanalysis 16 (2004) $1427-1433$.

[27] J.M.P.J. Garrido, C. Delerue-Matos, F. Borges, T.R.A. Macedo, A.M. Oliveira-Brett, Voltammetric oxidation of drugs of abuse: III. Heroin and metabolites, Electroanalysis 16 (2004) 1497-1502.

[28] N. Milhazes, T. Cunha-Oliveira, P. Martins, J. Garrido, C. Oliveira, C.A. Rego, F. Borges, Synthesis and cytotoxic profile of 3,4methylenedioxymethamphetamine ("ecstasy") and its metabolites on undifferentiated PC12 cells: a putative structure-toxicity relationship, Chem. Res. Toxicol. 19 (2006) 1294-1304.

[29] A. Leo, C. Hansch, D. Elkins, Partition coefficients and their uses, Chem. Rev. 21 (1971) 525.

[30] G. Bouchard, P.-A. Carrupt, B. Testa, V. Gobry, H.H. Girault, Lipophilicity and solvation of anionic drugs, Chem. Eur. J. 8 (2002) 3478-3484.

[31] G. Bouchard, P.-A. Carrupt, B. Testa, V. Gobry, H.H. Girault, The apparent lipophilicity of quaternary ammonium ions is influenced by Galvani potential difference, not ion-pairing: a cyclic voltammetry study, Pharm. Res. 18 (2001) 702-708.

[32] R. Gulaboski, C.M. Pereira, M.N.D.S. Cordeiro, I. Bogeski, E. Ferreira, D. Ribeiro, M. Chirea, A.F. Silva, Electrochemical study of ion transfer of acetylcholine across the interface of water and a lipid-modified 1,2-dichloroethane, J. Phys. Chem. B 109 (2005) $12549-12559$.

[33] G. Bouchard, A. Galland, P.-A. Carrupt, R. Gulaboski, V. Mirceski, F. Scholz, H.H. Girault, Standard partition coefficients of anionic drugs in the $n$-octanol/water system determined by voltammetry at three-phase electrodes, Phys. Chem. Chem. Phys. 5 (2003) 3748-3751.

[34] C. Bachmann, M.H. Bickel, History of drug metabolism: the first half of the 20th century, Drug Metab. Rev. 16 (1985-1986) $185-253$

[35] E.M. Cornford, L.D. Braun, W.H. Oldendorf, M.A. Hill, Comparison of lipid-mediated blood-brain barrier penetrability in neonates and adults, Am. J. Physiol. 243 (1982) C161-C168.

[36] E.J. Rook, A.D.R. Huitema, W. Van den Brink, J.M. Van Ree, J.H. Beijnen, Population pharmacokinetics of heroin and its major metabolites, Clin. Pharmacokinet. 45 (2006) 401-417.

[37] P. Buchwald, N. Bodor, Octanol-water partition: searching for predictive models, Curr. Med. Chem. 5 (1998) 353-380.

[38] H. Pajouhesh, G.R. Lenz, Medicinal chemical properties of successful central nervous system drugs, NeuroRx 2 (2005) 541-553.

[39] G. Kopman, H. Zhu, Recent methodologies for the estimation of $n$-octanol/water partition coefficients and their use in the prediction of membrane transport properties of drugs, Med. Chem. 5 (2005) 127-133. 